\title{
A 31 bp VNTR in the cystathionine $\beta$-synthase (CBS) gene is associated with reduced CBS activity and elevated post-load homocysteine levels
}

\author{
Karin JA Lievers $^{1}$, Leo AJ Kluijtmans ${ }^{1}$, Sandra G Heil ${ }^{1}$, Godfried HJ Boers ${ }^{2}$, Petra Verhoef ${ }^{4}$, \\ Dinny van Oppenraay-Emmerzaal ${ }^{1}$, Martin den Heijer ${ }^{3}$, Frans JM Trijbels ${ }^{1}$ and \\ Henk J Blom*,1
}

\begin{abstract}
${ }^{1}$ Department of Pediatrics, University Medical Center Nijmegen, The Netherlands; ${ }^{2}$ Department of Internal Medicine, University Medical Center Nijmegen, The Netherlands; ${ }^{3}$ Division of Endocrinology, University Medical Center Nijmegen, The Netherlands; ${ }^{4}$ Wageningen Center for Food Sciences and Division of Human Nutrition and Epidemiology, Wageningen University, Wageningen, The Netherlands
\end{abstract}

Molecular defects in genes encoding enzymes involved in homocysteine metabolism may account for mild hyperhomocysteinaemia, an independent and graded risk factor for cardiovascular disease (CVD). Although heterozygosity for cystathionine $\beta$-synthase (CBS) deficiency has been excluded as a major genetic cause of mild hyperhomocysteinaemia in vascular disease, mutations in (non-)coding DNA sequences may lead to a mildly decreased CBS expression and, consequently, to elevated plasma homocysteine levels. We assessed the association between a 31 bp VNTR, that spans the exon 13-intron 13 boundary of the CBS gene, and fasting, post-methionine load and increase upon methionine load plasma homocysteine levels in 190 patients with arterial occlusive disease, and in 381 controls. The 31 bp VNTR consists of 16, 17, 18, 19 or 21 repeat units and shows a significant increase in plasma homocysteine concentrations with an increasing number of repeat elements, in particular after methionine loading. In 26 vascular disease patients the relationship between this $31 \mathrm{bp}$ VNTR and CBS enzyme activity in cultured fibroblasts was studied. The CBS enzyme activity decreased with increasing number of repeat units of the $31 \mathrm{bp}$ VNTR. RT-PCR experiments showed evidence of alternative splicing at the exon 13-intron 13 splice junction site. The $31 \mathrm{bp} \mathrm{VNTR} \mathrm{in} \mathrm{the} \mathrm{CBS} \mathrm{gene} \mathrm{is} \mathrm{associated}$ with post-methionine load hyperhomocysteinaemia that may predispose individuals to an increased risk of cardiovascular diseases. European Journal of Human Genetics (2001) 9, 583-589.

Keywords: cystathionine $\beta$-synthase (CBS); cardiovascular disease; homocysteine; hyperhomocysteinaemia; VNTR

\section{Introduction}

Cardiovascular disease is a complex multi-factorial trait, and is the leading cause of death in the industrialised world. ${ }^{1,2}$ Multi-factorial diseases are originating from interactions of genes and environmental factors that create a gradient of genetic susceptibility to disease. Established risk factors for

*Correspondence: HJ Blom, Department of Pediatrics, UMC Nijmegen, PO Box 9101, 6500 HB, Nijmegen, The Netherlands. Tel: +31 24 3613469; Fax: +31 24 3618900; E-mail: H.Blom@ckslkn.azn.nl Received 19 February 2001; revised 17 April 2001; accepted 1 May 2001 cardiovascular disease include elevated blood cholesterol, hypertension, diabetes mellitus and tobacco smoking. A mildly elevated plasma homocysteine concentration is generally, ${ }^{3-5}$ but not universally ${ }^{6}$ accepted as an independent and graded risk factor for both arterial occlusive disease and venous thrombosis.

Homocysteine is a branch-point intermediate of methionine metabolism, and can be irreversibly committed to transsulphuration by the vitamin $\mathrm{B}_{6}$-dependent enzyme, cystathionine $\beta$-synthase (CBS). Alternatively, homocysteine can be remethylated to methionine in a reaction catalysed by the vitamin $\mathrm{B}_{12}$-dependent enzyme methio- 
nine synthase (MS). The latter enzyme requires 5methyltetrahydrofolate as a co-substrate, which is formed upon reduction of 5,10-methylenetetrahydrofolate by methylenetetrahydrofolate reductase (MTHFR). Genetic defects in genes encoding these enzymes, or depletion of important cofactors or (co)substrates for those enzymes, including folate, vitamin $\mathrm{B}_{12}$ and vitamin $\mathrm{B}_{6}$ may result in elevated plasma homocysteine. ${ }^{7,8}$

In the last decade, several studies have been conducted to elucidate the genetic determinants of mild hyperhomocysteinaemia in patients with premature cardiovascular disease. Hereditary defects in homocysteine metabolisms have been investigated by enzymatic and molecular genetic techniques. In 1985, Boers et $a l^{9}$ reported decreased CBS activities in extracts of cultured fibroblasts of hyperhomocysteinaemic vascular disease patients, which were comparable to those observed in obligate heterozygotes for CBS deficiency; similar results were described by Clarke et $a l^{10}$ in $80 \%$ of their hyperhomocysteinaemic patients. Both studies concluded that vascular disease patients with hyperhomocysteinaemia were presumably heterozygotes for CBS deficiency, ${ }^{9,10}$ a finding hard to reconcile with an earlier observation by Mudd et $a l^{11}$ The finding of decreased CBS activities in cultured fibroblasts from hyperhomocysteinaemic vascular disease patients in the range of obligate heterozygotes, however, could not be reproduced, ${ }^{12,13}$ and still needs clarification.

The isolation and characterisation of the CBS $\mathrm{CDNA}^{14}$ permitted the molecular genetic analysis of the CBS cDNA in patients with vascular disease. All genetic studies reported so far, failed to detect an involvement of heterozygosity for CBS deficiency in hyperhomocysteinaemia and premature vascular disease. ${ }^{13,15,16}$ These studies, however, do not exclude an involvement of mildly impaired CBS function in hyperhomocysteinaemia and vascular disease. Most genetic studies performed thus far, only explored the CBS coding region, and did not examine the non-coding regions of the CBS gene, for functional polymorphisms. As reported recently, genetic variation in these non-coding sequences may affect enzyme expression, transcript stability or splicing. ${ }^{17,18}$

In the present study, we analysed a variable number of tandem repeats (VNTR) of $31 \mathrm{bp}$ which spans the exon 13-intron 13 boundary of the CBS gene in 190 patients with arterial occlusive disease and in 381 populationbased controls. This VNTR was first described by Kraus et al. ${ }^{19}$ Each repeat unit contains a consensus splice donor site and this VNTR may therefore affect homocysteine metabolism. We report the allele frequencies and genotype distributions of this polymorphic variant in both cases and controls, and describe the association with fasting, post-methionine load and delta (ie increase upon methionine loading) plasma homocysteine concentrations.

\section{Materials and methods}

\section{Study population}

The study population consisted of a group of 130 cases with severe coronary occlusions and 101 population based controls. ${ }^{20}$ We extended our patient group with 60 patients with documented premature cardiovascular disease. ${ }^{13}$ To equalise the male-female ratio between the patient and control group, all 280 male controls from a second population-based control group ${ }^{21}$ were included.

Over the last 10 years, fibroblasts had been collected from 26 cardiovascular patients with mild hyperhomocysteinaemia. These selected patients are not included in the study group described above but we used the CBS activity measurements in these fibroblasts to assess a possible association between the different $31 \mathrm{bp}$ VNTR genotypes and CBS enzyme activity.

\section{Biochemical parameters}

Cases and controls were subjected to an oral methionine loading test as described by Boers et al. ${ }^{9}$ Total homocysteine was measured in plasma using high-performance liquid chromatography (HPLC), with reverse phase separation and fluorescence detection, as described by Te Poele-Pothoff et $a l .{ }^{22}$ All homocysteine measurements were conducted the University Medical Center Nijmegen, The Netherlands. Fasting and post-load plasma homocysteine levels were obtained from 555 and 525 individuals, respectively.

CBS activities in extracts of cultured skin fibroblasts were determined in the absence and presence of $1 \mathrm{~mm}$ pyridoxal 5 '-phosphate (PLP), essentially according to Engbersen et al. ${ }^{12}$ Activities are expressed in nmol cystathionine formed per $\mathrm{mg}$ protein per hour at $37^{\circ} \mathrm{C}$.

\section{Detection of the CBS 31 bp VNTR}

Genomic DNA was isolated from buffy coats by a standard method, ${ }^{23}$ and stored at $4{ }^{\circ} \mathrm{C}$ until analysis. Genomic DNA was available of 561 individuals.

After PCR amplification in standard PCR buffer, containing $100 \mathrm{ng}$ forward primer (5'-TGCAGCCGTCAGACCAAG-3') and $100 \mathrm{ng}$ reverse primer (5'-TTAAGTCCCCAAAACACGG3'), $200 \mu \mathrm{M}$ each dNTP, $1.5 \mathrm{~mm} \mathrm{MgCl}_{2}$ and using an annealing temperature of $52^{\circ} \mathrm{C}$, the $784-908$ bp DNA fragments were analysed on a $2 \%$ agarose gel. PCR products were sequenced on both strands using an ABI 377 automated DNA sequencer to analyse the exact DNA sequence of each allele.

\section{RT - PCR}

Total RNA was isolated from cultured fibroblasts using an established method, ${ }^{24}$ and reverse transcribed using Superscript II reverse transcriptase according to the manufacturer's recommendations (Life Technologies). The CBS cDNA was subsequently analysed for the inclusion of a part of intron 13 by PCR amplification using $100 \mathrm{ng}$ forward primer (5'GCACACCATCGAGATCCT-3'; cDNA \#1296-1313) and $100 \mathrm{ng}$ reverse primer (5'-GCCTGTAGGTGACTGGGT-3'), 
located in intron 13 (Figure 1). PCR was performed in standard PCR buffer including $200 \mu \mathrm{M}$ each dNTP and $3 \mathrm{~mm}$ $\mathrm{MgCl}_{2}$ using the following profile: $3^{\prime} / 92^{\circ} \mathrm{C}, 35$ cycles of $1^{\prime} /$ $92^{\circ} \mathrm{C}, 1^{\prime} / 55^{\circ} \mathrm{C}, 1^{\prime} / 72^{\circ} \mathrm{C}$, and a final extension of $7^{\prime}$ at $72^{\circ} \mathrm{C}$. Amplification of alternatively spliced mRNA, in which at least the first repeat of intron 13 is retained, results in a 192 bp fragment, whereas amplification of any residual DNA in the RNA isolate results in a $772 \mathrm{bp}$ fragment (Figure 1). The 100 bp DNA ladder of Life Technologies was used as a marker.

\section{Statistical analysis}

Differences in genotype distributions were assessed by Pearson's chi-square analysis. Differences in homocysteine concentrations between cases and controls were assessed by Student's $t$-test, adjusted for age and gender by means of linear regression analysis. Plasma homocysteine concentrations showed positive skewness and were therefore logtransformed prior to all analyses. The differences in homocysteine concentrations between genotype subgroups were assessed by one-way analysis of variance (ANOVA) followed by Bonferroni corrected $t$-tests. Odds ratios (OR) and 95\% confidence intervals (95\% CI) for arterial occlusive disease, associated with elevated plasma homocysteine levels and with the different CBS genotypes, were calculated with logistic regression analysis. Tests for trend were performed with linear regression analysis. All $P$-values reported are twotailed, and statistical significance was accepted at $P<0.05$.

\section{Results}

Characteristics of study groups

Age, sex, and total plasma homocysteine concentrations (ie fasting, post methionine load, and net increase upon methionine loading or delta) of cases and controls are shown in Table 1 . The geometric mean age and the percentage males did not differ between cases and controls. Cases had a higher fasting homocysteine $(+5.7 \% ; P=0.011)$ and a higher homocysteine concentration after methionine loading $(+5.1 \%$; $P=0.045$ ). The net increase upon methionine loading (ie postload minus fasting homocysteine concentration) was slightly, but not significantly higher in cases compared with controls $(+5.7 \% ; P=0.13)$.

\section{VNTR genotype distributions and risk of arterial occlusive disease}

The 31 bp VNTR in intron 13 specifies five different alleles, with a variable number of tandem repeats, ie with $16,17,18$, 19 or 21 repeat elements. The 31 bp VNTR consists of 16 heterogeneous repeat units. The four alleles that were sequenced are combinations of these 16 different units (Figure 1). The first eight repeat units $(\mathrm{A}-\mathrm{H})$ as well as the last three $(\mathrm{N}-\mathrm{P})$ are present in all four alleles. The alleles were named according to the number of repeat units. The most frequent allele with an allele frequency of $77.2 \%$ (patients and controls combined) contained 18 repeats, whereas the alleles that contained $16,17,19$ or 21 repeat units were less frequent with allele frequencies of $0.1,9.5,10.5$ and $2.7 \%$ respectively.

The VNTR genotype distributions in the two constituent case groups were similar, as were those in the two constituent control groups (data not shown). Genotype distributions for the VNTR were compared between cases and controls (Table 2 ). VNTR genotypes were investigated as risk genotypes in arterial occlusive disease. The differences in VNTR genotype frequencies between the combined cases and controls groups were not statistically significant (Table 2).

\section{Association VNTR genotypes and plasma homocysteine} Fasting, post-load and delta plasma homocysteine concentrations were determined, and their association with the VNTR genotypes was studied (Table 2). Because associations between VNTR genotypes and plasma homocysteine were similar in cases and controls (data not shown), we combined cases and controls to increase statistical power.

The different genotypes defined by the $31 \mathrm{bp}$ VNTR significantly influenced post-load as well as delta homocysteine concentrations (ANOVA $P=0.002$ and $P=0.003$ respectively; Table 2). When the homozygous genotypes
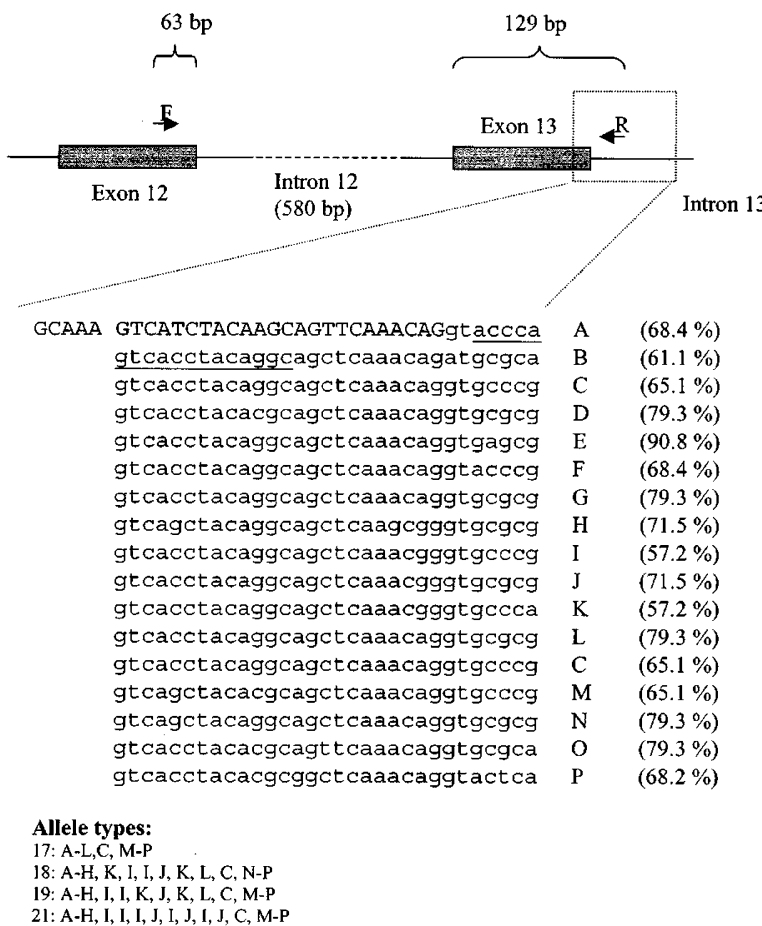

Figure 1 VNTR in exon 13/intron 13 of the CBS gene. F and R indicate the forward and reverse primers used in RT-PCR. The sequence of allele 17 is shown. The exonic sequence is indicated in capital letters; the underlined sequence indicates the localisation of the reverse primer. The percentages indicate the weight estimates for splice donor sites according to Shapiro and Senapathy. ${ }^{29}$ 
Table 1 Characteristics and plasma homocysteine concentrations in cases and controls and 31 bp VNTR genotype distribution in cases and controls

\begin{tabular}{|c|c|c|c|}
\hline & $\begin{array}{l}\text { Cases } \\
(n=190)\end{array}$ & $\begin{array}{l}\text { Controls } \\
(n=381)\end{array}$ & $P^{*}$ \\
\hline Age (years) & $49.0 \pm 10.2$ & $50.8 \pm 11.9$ & 0.11 \\
\hline Sex (\% male) & $75.3^{-}$ & $74.3^{-}$ & $0.80^{\dagger}$ \\
\hline Fasting homocysteine $(\mu \mathrm{mol} / \mathrm{l})$ & $14.4(13.7-15.1)$ & $13.4(13.0-13.9)$ & 0.011 \\
\hline Post-load homocysteine $(\mu \mathrm{mol} / \mathrm{l})$ & $41.3(39.4-43.3)$ & $39.1(38.0-40.3)$ & 0.045 \\
\hline Post-load increase $(\mu \mathrm{mol} / \mathrm{l})$ & $26.1(24.6-27.7)$ & $24.7(23.6-25.9)$ & $0.13^{\ddagger}$ \\
\hline Genotype 31 bp VNTR: & & $N(\%)$ & \\
\hline $16-17$ & 0 & $1(0.3)$ & \\
\hline $17-17$ & $5(2.8)$ & $7(2.1)$ & \\
\hline $17-18$ & $21(11.7)$ & $43(12.9)$ & \\
\hline $17-19$ & $3(1.7)$ & $3(0.9)$ & \\
\hline $17-21$ & $1(0.6)$ & $1(0.3)$ & \\
\hline $18-18$ & $103(57.5)$ & $211(63.2)$ & \\
\hline $18-19$ & $31(17.3)$ & $51(15.3)$ & \\
\hline $18-21$ & $11(6.1)$ & $7(2.1)$ & \\
\hline $19-19$ & $2(1.1)$ & $6(1.8)$ & \\
\hline $19-21$ & 0 & $4(1.1)$ & \\
\hline $21-21$ & $2(1.1)$ & $\chi^{2}=13.86 ; P=0.18$ & \\
\hline
\end{tabular}

Age is expressed as mean \pm SD and homocysteine concentrations as geometric means $(95 \% \mathrm{Cl}) .{ }^{*}$ Student's $t$ test; ${ }^{\dagger}$ Pearson $\chi^{2}$ test; ${ }^{\star}$ Adjusted for age and sex.

Table 2 The relationship between total plasma homocysteine and CBS genotypes

\begin{tabular}{llll}
\hline $\begin{array}{l}31 \text { bp VNTR } \\
\text { genotype }\end{array}$ & $\begin{array}{l}\text { Fasting homocysteine } \\
(\mu \mathrm{mol} / \mathrm{I})\end{array}$ & $\begin{array}{l}\text { Post-load homocysteine } \\
(\mu \mathrm{mol} / \mathrm{I})\end{array}$ & $\begin{array}{l}\text { Post-load increase } \\
(\mu \mathrm{mol} / \mathrm{I})\end{array}$ \\
\hline $16-17$ & $15.6\{1\}$ & $49.0\{1\}$ & $33.4\{1\}$ \\
$17-17$ & $13.9(10.8-17.9)\{11\}$ & $37.5(32.1-43.7)\{11\}$ & $22.6(18.6-27.5)\{11\}$ \\
$17-18$ & $12.8(11.8-13.8)\{63\}$ & $35.2(32.7-37.9)\{60\}$ & $21.9(19.9-24.0)\{60\}$ \\
$17-19$ & $14.0(11.1-17.6)\{7\}$ & $35.4(27.6-45.4)\{7\}$ & $21.3(16.0-28.2)\{7\}$ \\
$17-21$ & $11.7(2.3-59.1)\{2\}$ & $36.8(2.6-515.7)\{2\}$ & $25.0(1.1-565.8)\{2\}$ \\
$18-18$ & $13.8(13.3-14.3)\{305\}$ & $41.1(39.7-42.5)^{*}\{289\}$ & $26.7(25.6-27.8)\{288\}$ \\
$18-19$ & $13.6(12.6-14.6)\{78\}$ & $37.8(35.1-40.6)\{73\}$ & $24.3(22.4-26.3)\{72\}$ \\
$18-21$ & $14.2(12.2-16.4)\{18\}$ & $40.6(36.6-45.0)\{18\}$ & $25.2(21.2-30.1)\{18\}$ \\
$19-19$ & $16.8(10.6-26.8)\{8\}$ & $46.8(33.7-65.0)\{7\}$ & $26.8(16.9-42.5)\{7\}$ \\
$19-21$ & $13.8(7.3-26.2)\{4\}$ & $51.3(39.0-67.5)\{3\}$ & $37.3(29.1-47.7)\{3\}$ \\
$21-21$ & $17.6(13.2-23.4)\{2\}$ & $65.0(44.2-95.7)\{2\}$ & $47.4(31.0-72.4)\{2\}$ \\
& $P=0.286^{\dagger}$ & $P=0.002^{\dagger}$ & $P=0.003^{\dagger}$ \\
\hline
\end{tabular}

For the association between genotype and homocysteine concentrations (expressed as geometric means $(95 \% \mathrm{Cl})\{\mathrm{N}\}$ ), cases and controls were combined. ${ }^{\dagger}$ ANOVA on log transformed data; ${ }^{*} P=0.011$ vs 17-18 (Bonferroni-corrected $t$-test).

were considered separately, individuals with the 17-17 genotype had the lowest geometric mean post-load homocysteine concentration $(37.5 \mu \mathrm{mol} / \mathrm{l})$. The two homozygotes with the 21-21 genotype had a post-load homocysteine concentration of 63.0 and $65.0 \mu \mathrm{mol} / 1$ respectively, while those with the 18-18 and 19-19 genotypes showed intermediate geometric mean homocysteine concentrations of 41.1 and $46.8 \mu \mathrm{mol} / 1$, respectively (ANOVA $P=0.067$; test for linear trend $P=0.013$; Figure 2). This clearly demonstrates the positive association between the number of repeat units and post-load homocysteine concentrations.

To elucidate the exact DNA sequence of every allele defined by this $31 \mathrm{bp}$ VNTR, and to find a potential explanation for the increasing homocysteine concentrations, we sequenced the VNTR in homozygotes for each of the alleles (Figure 1). Each repeat unit contains the splice donor site between exon 13 and its following intron. Therefore, the published exonintron boundary is followed by at least 15 repeat units that differ only slightly in nucleotide sequence and carry all a potential splice donor site (Figure 1, A-P). RT-PCR experiments were performed to determine whether the first part of intron 13 was retained in at least some of the CBS mRNAs. PCR on cDNA with a reverse primer in intron 13 (primer In13R, Figure 1) indeed showed a fragment of $192 \mathrm{bp}$, indicating that alternative splicing does occur and that intron 13 is not completely spliced out (Figure 3 ). This could lead to abnormal CBS protein, and therefore decreased CBS enzyme activity. 


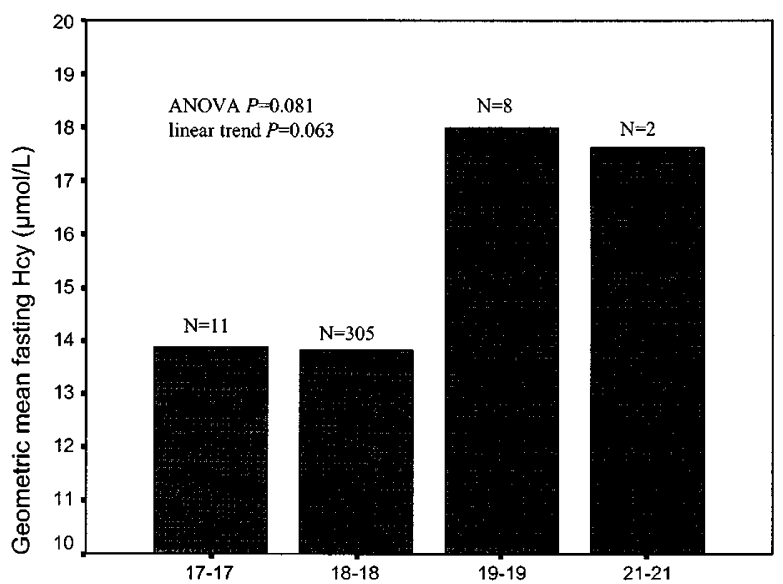

A. Homozygotes 31 bp VNTR

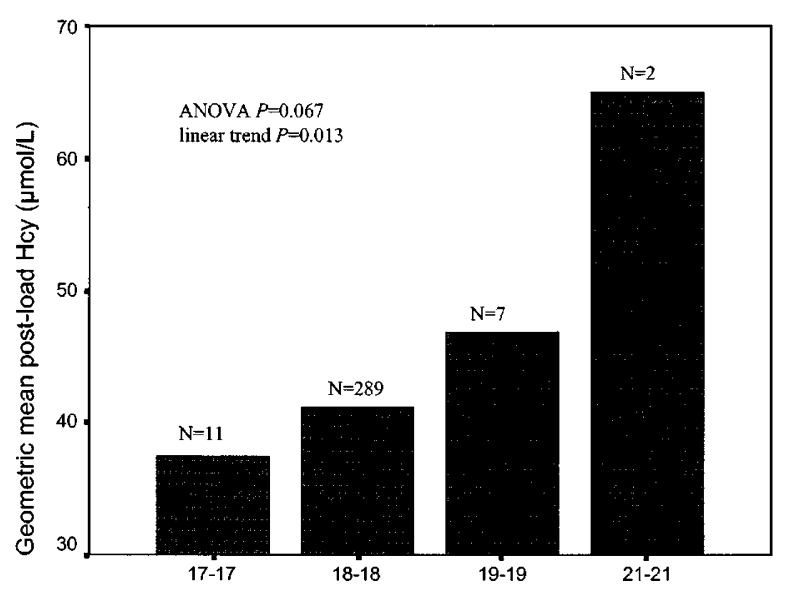

B. Homozygotes 31 bp VNTR

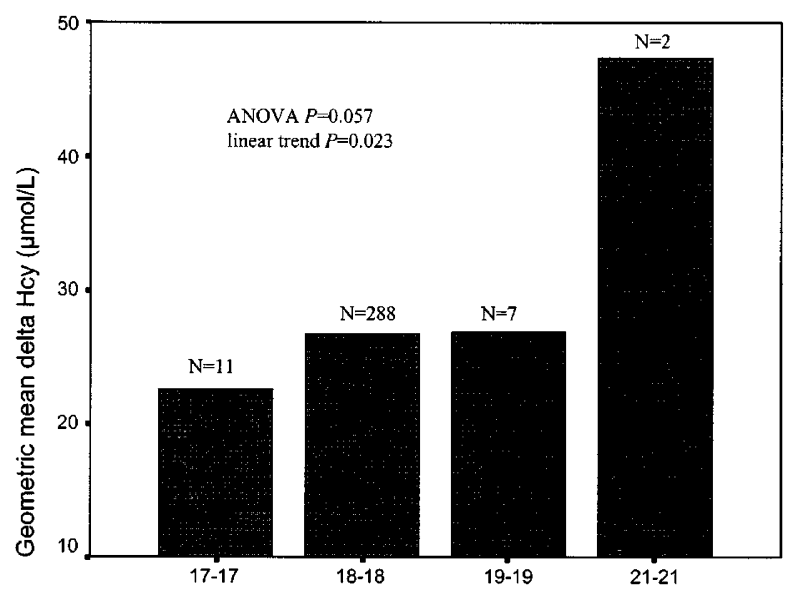

C. Homozygotes 31 bp VNTR

Figure 2 Relationship between fasting A, post-load B and increase upon methionine load $\mathbf{C}$ homocysteine concentrations and homozygous genotypes defined by the $31 \mathrm{bp}$ VNTR.
We determined the 31 bp VNTR genotype in 26 individuals, from whom CBS activities had been measured in cultured fibroblasts, and found a clear negative association between CBS enzyme activity and the number of repeat units ( - PLP: ANOVA $P=0.035$; + PLP: ANOVA $P=0.021$; Figure 4 ).

\section{Discussion}

A mildly elevated plasma homocysteine concentration has been shown to be an independent risk factor for cardiovas-

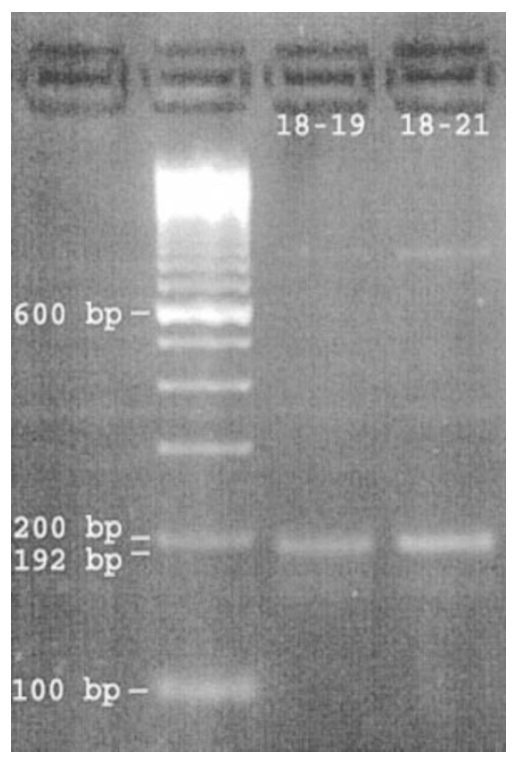

Figure 3 Results of the RT-PCR. 18-19 and 18-21 denote VNTR genotype. The presence of the $192 \mathrm{bp}$ cDNA fragment indicates alternatively spliced CBS mRNA.

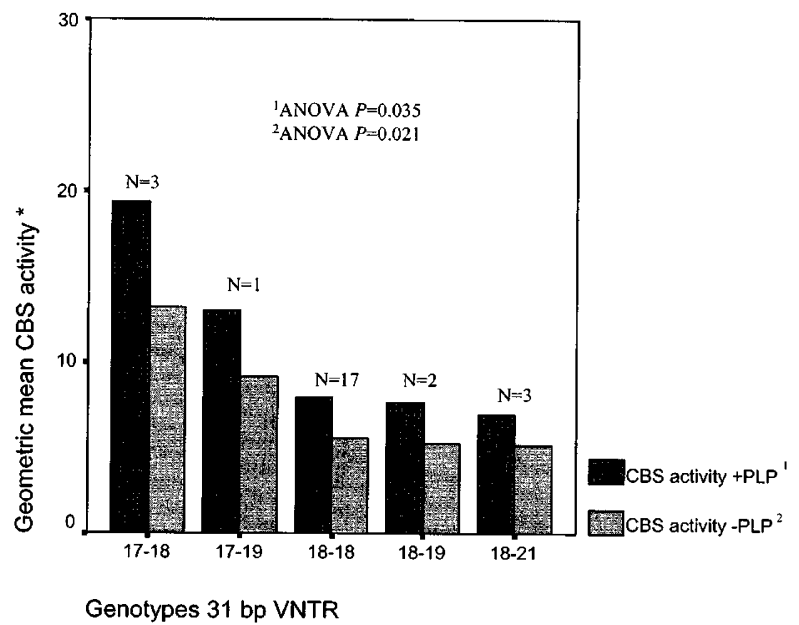

Figure 4 Relationship between CBS enzyme activity and the $31 \mathrm{bp}$ VNTR. *CBS enzyme activities in extracts of cultured fibroblasts are expressed in nmol cystathionine formed per $\mathrm{mg}$ protein per hour at $37^{\circ} \mathrm{C}$. 
cular disease in both prospective $\mathrm{e}^{3,25}$ and retrospective $\mathrm{e}^{5,9,10,20}$ case-control studies. Although most studies only assessed the relationship between fasting hyperhomocysteinaemia and the risk of CVD, several studies also report on the association between elevated post methionine load homocysteine concentrations as a risk factor for cardiovascular disease, independently from an elevated fasting level. ${ }^{9,10,20,26,27}$ As methionine loading has been postulated to provocate in particular the transsulphuration pathway, ${ }^{28}$ in which CBS is the regulating enzyme, these data suggest the involvement of suboptimal CBS function in hyperhomocysteinaemia after methionine loading and, consequently, increased cardiovascular risk.

In the present study, we analysed a 31 bp VNTR in exon 13intron 13 of the CBS gene, as a potential contributor to the risk of arterial occlusive disease. No differences in genotype distributions or allele frequencies were found between cases and controls, indicating that no particular VNTR genotype is over-represented in arterial occlusive disease patients compared with controls.

We also investigated the associations between the VNTR genotypes and fasting and post-load plasma homocysteine concentrations. Post-load homocysteine concentrations and net increase upon methionine loading were positively associated with the $31 \mathrm{bp}$ VNTR; plasma homocysteine concentrations increased with the number of repeats (Table 2 and Figure 2).

Four alleles of the VNTR (ie with 17, 18, 19 and 21 repeat units) were sequenced to elucidate (i) the exact sequence of each allele, and (ii) a possible mechanism by which this $31 \mathrm{bp}$ VNTR may affect homocysteine concentrations. In each allele, the first repeat unit (designated A) contains the postulated splice donor site between exon 13 and intron $13 .{ }^{19}$ Every following repeat unit also contains a functional splice donor site according to the consensus sequence for splice signals ${ }^{29}$ (Figure 1). Using appropriate weights, we calculated the weight estimate for each possible splice site in each repeat unit (Figure 1). The presence of multiple potential splice sites at the local DNA sequence environment increases the likelihood of their utilisation as an alternative splice site. ${ }^{30}$ Therefore, it is not unlikely that with every extra repeat unit an additional potential splice donor site is added, which increases the probability that these alternative splice sites are used in addition to the actual splice site in the first repeat unit of $31 \mathrm{bp}$. This hypothesis is supported by studies on Saccharomyces pombe and Drosophila melanogaster that show that expanding small introns in these organisms inhibits splicing of the intron or activates cryptic sites within the expanded introns. ${ }^{31}$ The smallest size of intron 13 of the CBS gene is $1196 \mathrm{bp}$ (allele 16) and the longer alleles defined by the $31 \mathrm{bp}$ VNTR lead to relatively large increases in the intron size. The length of intron 13 with $17,18,19$ and 21 repeat units are respectively, 1227, 1258, 1289 and $1351 \mathrm{bp}$, adding an additional $2.6,5.2,7.8$ and $13.0 \%$, respectively. It can be postulated that with increasing length of intron 13 due to an increased number of the repeat elements, the more likely it is that an alternative splice donor site is used.

We used RT-PCR techniques to analyse whether any alternative splicing actually occurs, and obtained evidence that the first part of intron 13 is still present in a significant proportion of the CBS mRNA population (Figure 3). This demonstrates that either the entire intron 13 is retained in some mRNAs, leading to a premature stop codon, or that alternative splice donor sites downstream of this repeat are also used, which cause frame shifts. The observation of a modified splicing pattern by a VNTR has also been described for the human interferon-inducible gene $6-16 .{ }^{32}$ In this gene, a partially expressed minisatellite was detected, that consisted of 26 tandemly repeated dodecanucleotides. The splice donor site of exon 2 is a component of the most upstream element of the tandem repeat. It was shown that the two neighbouring repeat units also provide functional splice

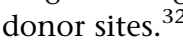

The association between the number of repeat elements and elevated post-load plasma homocysteine levels, potentially caused by aberrant splicing, is further substantiated by the observation of decreased CBS activities in fibroblasts of individuals with genotypes that include a high number of repeat elements. CBS enzyme activity decreased with increasing number of repeat elements (Figure 4). This association also underlines the existence of abnormal CBS protein leading to suboptimal CBS function.

Very recently, Yang et $a l^{33}$ reported new findings on this VNTR, in 398 coronary artery disease patients and in 137 apparently healthy controls. While they report a similar association between the $31 \mathrm{bp}$ VNTR and post-load plasma homocysteine levels, their study does not include an examination of CBS enzyme activities nor a detailed analysis on potential causes of this association. The present study clearly demonstrates that the length of the $31 \mathrm{bp}$ VNTR is negatively associated with CBS enzyme activity for which a plausible explanation, ie the occurrence of alternative splicing at the exon 13-intron 13 boundary, is presented. The increased homocysteine concentrations, associated with the increasing number of repeat elements, may predispose individuals to an increased risk of cardiovascular disease.

\section{Acknowledgments}

This study was, in part, supported by grants 93.176 and 97.071 from The Netherlands Heart Foundation. Dr Leo AJ Kluijtmans is a postdoctoral fellow of The Netherlands Heart Foundation (D99.023) and Dr. Henk J Blom is an Established Investigator of The Netherlands Heart Foundation (D97.021). 


\section{References}

1 Ross R: The pathogenesis of atherosclerosis: a perspective for the 1990s. Nature 1993; 362: 801-809.

2 Keating MT and Sanguinetti MC: Molecular genetic insights into cardiovascular disease. Science 1996; 272: 681-685.

3 Stampfer MJ, Malinow MR, Willett WC et al: A prospective study of plasma homocyst(e)ine and risk of myocardial infarction in US physicians. JAMA 1992; 268: 877-881.

4 Wald NJ, Watt HC, Law MR, Weir DG, McPartlin J, Scott JM: Homocysteine and ischemic heart disease: results of a prospective study with implications regarding prevention. Arch Intern Med 1998; 158: 862-867.

5 Den Heijer M, Koster T, Blom HJ et al: Hyperhomocysteinemia as a risk factor for deep-vein thrombosis. N Engl J Med 1996; 334: $759-762$.

6 Folsom AR, Nieto FJ, McGovern PG et al: Prospective study of coronary heart disease incidence in relation to fasting total homocysteine, related genetic polymorphisms, and B vitamins: the Atherosclerosis Risk in Communities (ARIC) study. Circulation 1998; 98: 204-210.

7 Frosst P, Blom HJ, Milos R et al: A candidate genetic risk factor for vascular disease: a common mutation in methylenetetrahydrofolate reductase. Nat Genet 1995; 10: 111-113.

8 Selhub J, Jacques PF, Wilson PW, Rush D, Rosenberg IH: Vitamin status and intake as primary determinants of homocysteinemia in an elderly population. JAMA 1993; 270: 2693-2698.

9 Boers GH, Smals AG, Trijbels FJ et al: Heterozygosity for homocystinuria in premature peripheral and cerebral occlusive arterial disease. N Engl J Med 1985; 313: $709-715$.

10 Clarke R, Daly L, Robinson K et al: Hyperhomocysteinemia: an independent risk factor for vascular disease. N Engl J Med 1991; 324: 1149 - 1155 .

11 Mudd SH, Havlik R, Levy HL, McKusick VA, Feinleib M: A study of cardiovascular risk in heterozygotes for homocystinuria. Am J Hum Genet 1981; 33: 883-893.

12 Engbersen AM, Franken DG, Boers GH, Stevens EM, Trijbels FJ, Blom HJ: Thermolabile 5,10-methylenetetrahydrofolate reductase as a cause of mild hyperhomocysteinemia. Am J Hum Genet 1995; 56: $142-150$.

13 Kluijtmans LA, van den Heuvel LP, Boers GH et al: Molecular genetic analysis in mild hyperhomocysteinemia: a common mutation in the methylenetetrahydrofolate reductase gene is a genetic risk factor for cardiovascular disease. Am J Hum Genet 1996; 58: $35-41$.

14 Kraus JP, Le K, Swaroop M et al: Human cystathionine betasynthase cDNA: sequence, alternative splicing and expression in cultured cells. Hum Mol Genet 1993; 2: 1633-1638.

15 Kozich V, Kraus E, de Franchis R et al: Hyperhomocysteinemia in premature arterial disease: examination of cystathionine betasynthase alleles at the molecular level. Hum Mol Genet 1995; 4: $623-629$.

16 Gallagher PM, Meleady R, Shields DC et al: Homocysteine and risk of premature coronary heart disease. Evidence for a common gene mutation. Circulation 1996; 94: 2154-2158.

17 Suzuki K, Kuriyama M, Saito T, Ichinose A: Plasma lipoprotein(a) levels and expression of the apolipoprotein(a) gene are dependent on the nucleotide polymorphisms in its $5^{\prime}$-flanking region. J Clin Invest 1997; 99: 1361-1366.
18 Inoue I, Nakajima T, Williams CS et al: A nucleotide substitution in the promoter of human angiotensinogen is associated with essential hypertension and affects basal transcription in vitro. $J$ Clin Invest 1997; 99: 1786-1797.

19 Kraus JP, Oliveriusova J, Sokolova J et al: The human cystathionine beta-synthase (CBS) gene: complete sequence, alternative splicing, and polymorphisms. Genomics 1998; 52: $312-324$.

20 Verhoef P, Kok FJ, Kruyssen DA et al. Plasma total homocysteine, B vitamins, and risk of coronary atherosclerosis. Arterioscler Thromb Vasc Biol 1997; 17: 989-995.

21 Den Heijer M, Blom HJ, Gerrits WB et al: Is hyperhomocysteinaemia a risk factor for recurrent venous thrombosis? Lancet 1995; 345: $882-885$

22 Te Poele-Pothoff MT, van den Berg M, Franken DG et al: Three different methods for the determination of total homocysteine in plasma. Ann Clin Biochem 1995; 32: 218-220.

23 Miller SA, Dykes DD, Polesky HF: A simple salting out procedure for extracting DNA from human nucleated cells. Nucleic Acids Res 1988; 16: 1215 .

24 Chomczynski P, Sacchi N: Single-step method of RNA isolation by acid guanidinium thiocyanate-phenol-chloroform extraction. Anal Biochem 1987; 162: 156-159.

25 Perry IJ, Refsum H, Morris RW, Ebrahim SB, Ueland PM, Shaper AG: Prospective study of serum total homocysteine concentration and risk of stroke in middle-aged British men. Lancet 1995; 346: $1395-1398$

26 Bostom AG, Jacques PF, Nadeau MR, Williams RR, Ellison RC, Selhub J: Post-methionine load hyperhomocysteinemia in persons with normal fasting total plasma homocysteine: initial results from the NHLBI Family Heart Study. Atherosclerosis 1995; 116: $147-151$.

27 Kang SS, Wong PW: Genetic and nongenetic factors for moderate hyperhomocyst(e)inemia. Atherosclerosis 1996; 119: $135-138$.

28 Finkelstein JD, Martin JJ: Methionine metabolism in mammals. Distribution of homocysteine between competing pathways. $J$ Biol Chem 1984; 259: 9508 -9513.

29 Shapiro MB, Senapathy P. RNA splice junctions of different classes of eukaryotes: sequence statistics and functional implications in gene expression. Nucleic Acids Res 1987; 15: 7155 7174

30 Krawczak M, Reiss J, Cooper DN: The mutational spectrum of single base-pair substitutions in mRNA splice junctions of human genes: causes and consequences. Hum Genet 1992; 90: $41-54$.

31 Guo M, Lo PC, Mount SM. Species-specific signals for the splicing of a short Drosophila intron in vitro. Mol Cell Biol 1993; 13: $1104-1118$.

32 Turri MG, Cuin KA, Porter AC: Characterisation of a novel minisatellite that provides multiple splice donor sites in an interferon-induced transcript. Nucleic Acids Res 1995; 23: $1854-$ 1861.

33 Yang F, Hanson NQ, Schwichtenberg K, Tsai MY: Variable number tandem repeat in exon/intron border of the cystathionine beta-synthase gene: a single nucleotide substitution in the second repeat prevents multiple alternate splicing. Am J Med Genet 2000; 95: $385-390$. 